\title{
Application of GIS techniques to analysis of spatial distribution patterns of loom-weights, spindle-whorls and tokens at Pistiros, ancient Thrace, within a domestic/urban context
}

\author{
Małgorzata Grzybalska
}

School of Archaeology, Classics and Egyptology. The University of Liverpool. UK.

\begin{abstract}
Resumen
I am PhD student at The University of Liverpool. My doctoral research focuses on the analysis of domestic dietary habits in the Classical East Mediterranean by the application of GIS distribution patterns. I completed my second Master's thesis on 'Public space in the North Greek. Aegean and the Black Sea region in the fifth and fourth centuries B.C." at The University of Liverpool (2006). I have submitted my first Master Thesis on "Housing construction in ancient Greece in the classical age based on the example of Olynthus" at The University of Wroctaw (2005). My Bachelor dissertation on "Private architecture on Crete in the Iron and Bronze Age" was submitted at The University of Wrockaw (2003).
\end{abstract}

Key words: $\quad$ DIETARY HABITS; DISTRIBUTION PATTERNS; DOMESTIC ARCHITECTURE; PUBLIC SPACE; MEDITERRANEAN REGION.

\begin{abstract}
A long-term systematic international excavation project has attested the existence of a wide range of past human activities in the emporion Pistiros. An assemblage of artefacts indicating the conduct of different economic activities on the site includes an interesting collection of loom-weights, spindle-whorls and tokens. The purpose of this paper is to look at archaeological material from social, cultural and economic perspectives to understood fully the everyday life of the inhabitants of this trading centre from the Classical to early Hellenistic period (second half of the fifth to second centuries B.C.). To achieve this goal spatial mapping techniques (GIS) were applied to analyse distribution patterns of objects associated with the textile industry within a domestic context.
\end{abstract}

Key words: CLASSICAL PERIOD; DOMESTIC SPACE; SPATIAL MAPPING; LOOM WEIGHTS; EMPORION PISTIROS.

\section{Introduction}

The research described in the following article is concerned with an investigation of spatial distribution patterns of artefacts associated with the textile industry by the application of GIS software. I have chosen to explore archaeological finds in a domestic context from the ancient trading centre in ancient Thrace which was probably called Pistiros. The analysis comprises material from the middle classical and early Hellenistic period (second half of the fifth to second centuries B.C.).

Weaving and spinning were very important economic activities, usually performed within domestic areas by females in the household. Both loom weights and spindle whorls have been found in Pistiros. Interesting variations in their shape, size, weight and decoration were observed. Usage of GIS techniques to detect spatial patterns of distribution of finds associated with weaving can reveal important economic, social and cultural aspects of the existence of people living in the emporion in the 5 th and 4 th/3rd centuries B.C. Interpretation of maps that present the distribution of loom weights, spindle whorls and tokens also makes it possible to analyse the use of space within domestic/urban contexts at Pistiros.

\section{Research aims}

The analysis of available archaeological material and patterns of spatial distribution of artefacts associated with weaving can enable us to understand the following issues:

- Social, cultural and economic aspects of people living in the emporion in the classical and early Hellenistic period;

- Mutual interaction between Thracians and Greeks creating an interesting mixed population at Pistiros;

- Gender relationships distinguished by particular type of economic activity;

- The status of females associated with weaving;

- Personality and character (to some extent) of women using specific loom weights and spindle whorls;

- Other use of objects related to textile industry;

- Arrangement and use of space in domestic context;

3. Presentation of the archaeological material from the site 
An assemblage of spinning and weaving equipment spread across private space among ruins of the classical emporion presents a rich collection of types and shapes listed below (BOUZEK, 1996: 119- 176):

types/shapes of loom-weights:

a) pyramidal (type A) (fig. 1),

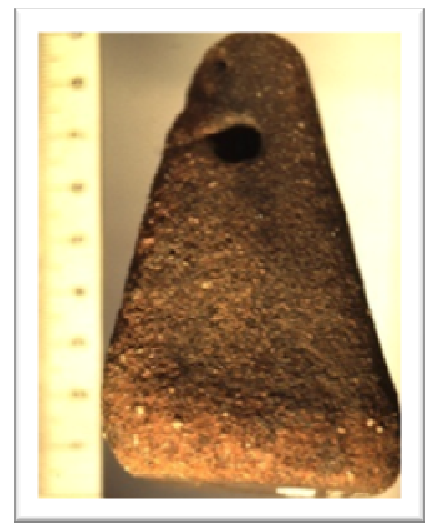

Figure 1. Pyramidal loom-weight of type A from trench B21 [60] (picture taken by Z. H. Arcbibald)

b) fiddle-shaped (type B) (Fig. 2),

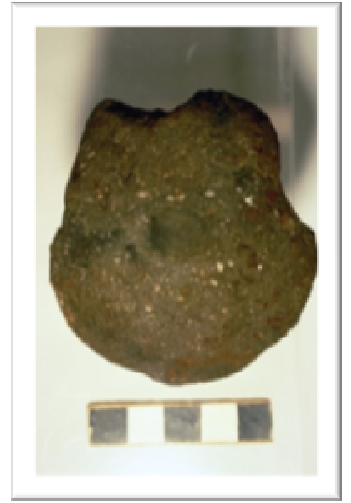

Figure 2. Fiddle-shaped loom-weight of type B from sector AB1 (picture made by Z. H. Archibald);

c) circular (type C) (Fig. 3),

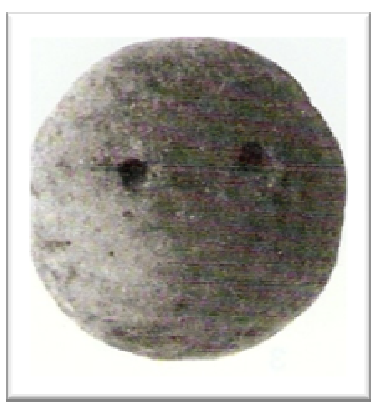

Figure 3. Circular loom-weight of type C (after Bouzek, 1996: Pl. XLIV. 11.11: 1)

d) prismatic or irregular,

e) with one or two wholes,

f) decorated with pattern,

g) decorated with letters,

h) undecorated/plain objects,

types/shapes of spindle-whorls:

a) flat circular (Fig. 4),

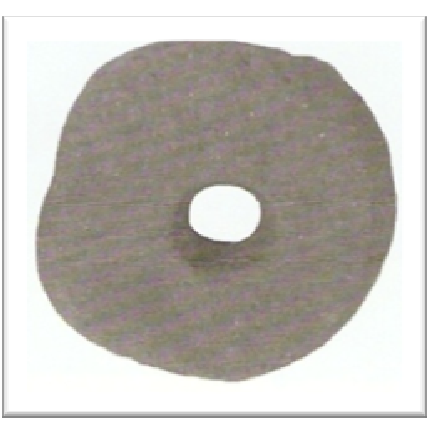

Figure 4. Flat circular spindle-whorl (after Bouzek, 1996: Pl. XLVII. 11.14:9)

b) flat disk (Fig. 5),

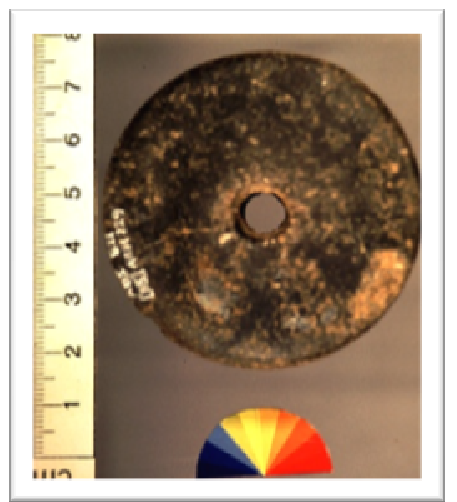

Figure 5. Flat circular spindle-whorl from trench B21 857 (picture made by Z. H. Archibald) 


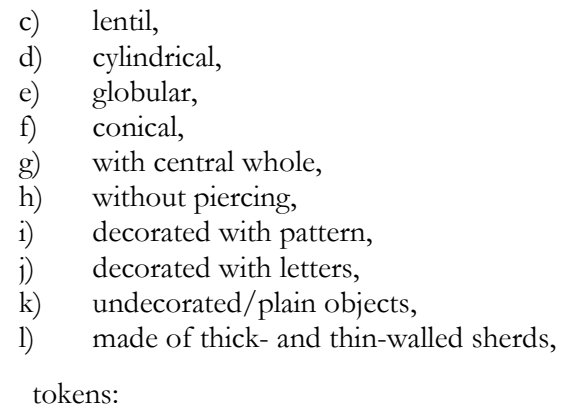

a) similar to spindle-whorls (Fig. 6),

b) without aperture,

c) rounded in shape,

d) made of sherds,

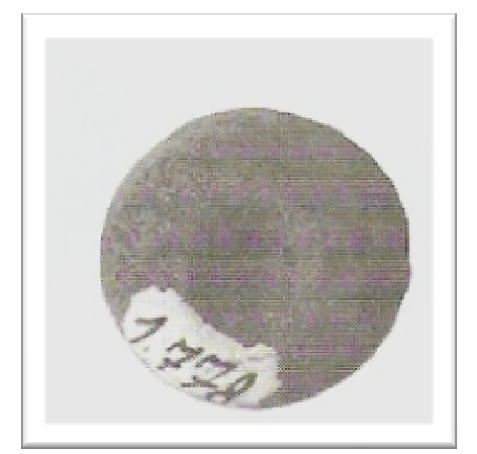

Figure 6. Token (after Bouzek, 1996: Pl. XLVI. 11.13:4)

\section{An analysis of spatial distribution of loom weights, spindle whorls and tokens within British trenches B21 and D19/24}

An archaeological excavations were conducted at Pistiros from 1994 onwards. A process of recording of both structures and artefacts in detailed and systematic manner enables to undertake spatial analysis of past human activities at this location. The entire collection of finds classified as 'special finds' was recorded in the "Inventory book" stored in the Museum at Septemvri. Additionally, these artefacts found within trenches B21 and D14/19 and D24 were recorded in the British version of "Special finds inventory book" too. Therefore, coordinates of all special finds should have been registered in these books. Unfortunately, Bulgarian system of recording coordinates differs from British one. Bulgarian system is based on tape measurements from the fixed point, whereas British team uses Electronic Distance Measurement (EDM). This is why, coordinates taken by Bulgarian archaeologists are not as accurate as those recorded by British researchers. Two various ways of recording coordinates for the same finds were the first problem which I have noticed during preparation of data for analysis. Coordinates of artefacts in the "Special finds inventory book" belonging to British team of archaeologists were recorded according to Bulgarian scheme. I was able to obtain EDM coordinates for some part of finds from trench B21, while coordinates taken for remaining group of archaeological material from square B21 and quadrates D14/19,
D24 were not available at the time of writing this paper. Therefore, I have prepared spatial distribution map in Arc GIS for artefacts possessing records of EDM coordinates from trench B21 (Map 1, Table 1). Afterwards, I have allocated data without EDM coordinates from squares B21 and D 14/19 and D24 to the contexts visible on the available plans in Auto Cad (Map 2, Map 3, Map 4, Table 3, Table 6).

Archaeological material from both trenches B21 and D 19/24 reveals traces of past human activities within domestic context in the classical and early Hellenistic period. Occupation deposits were observed for such contexts, as for example: brick and tile spread [25], layer associated with hearth [101], pits [84], [85], [43], [53] and [75], [76], muddy brown [58] and greish brown layers [64] with remains of loom-weights, spindle-whorls and tokens in quadrat B21 (Map 1, Map 2, Map 3, Table 3). Similarly, evidence of textile production was uncovered within pits [1021], [1029], [1030], [1031], [1060] and [1073], as well as within grey, grey-brown and yellowish-grey deposits [1004]. [1073], [1073] and [1076] across the trench D14/19 and D24 (Map 4, Table 6).

Total amount of sixty artefacts (forty nine loom-weights, seven spindle-whorls and four tokens) associated with textile production was excavated within trench B21 (Table 2, Table 4, Table 5, Chart 1). Square D19/24 contained twenty two finds (twenty one loom-weights and one spindle) documenting spinning and weaving activities (Table 7, Chart 2).

Furthermore, spatial distribution of loom-weights, spindlewhorls and tokens with available EDM coordinates within trench B21 exposes an interesting patterns (Map 1). Fiddleshaped loom-weights are concentrated in the northern and south-western part of the quadrat B21, whereas only one fiddleshaped loom-weight is located in the south-eastern corner of the trench. Pyramidal loom-weights are grouped mainly in the south-eastern section, while only two objects were observed in the south-western part of the square. Circular loom-weights are distributed throughout south-eastern and south south-western area of B21. Two spindle-whorls are situated in the western and eastern section respectively. Two tokens are visible in the south-western corner and one in the eastern part of the trench. One iron needle was discovered in the southern part of the square B21. General pattern of spatial distribution of artefacts can be detected within the trench B21 as well. Great accumulation of finds is clearly noticeable in the southern and eastern section, while archaeological material appears to be less densely concentrated in the northern and western area (Map 1).

Moreover pyramidal loom-weights were observed in the contexts [146] (Map 2) and [64] (Map 3), fiddle-shaped loomweights in the context [134] (Map 2) and circular loom-weights in the contexts [64] (Map 3).

These patterns of spatial distribution clearly indicates that space within B21 was destined for with textile production among other everyday activities performed within domestic area by female members of the household.

Archaeological evidence of weaving and spinning activities was uncovered in the trench D19/24. For instance, pyramidal loomweights were clustered in the contexts [1031] and [1033], fiddleshaped in the contexts [1004], [1021], [1029] and spindle-whorls in the context [1037] (Map 4). 


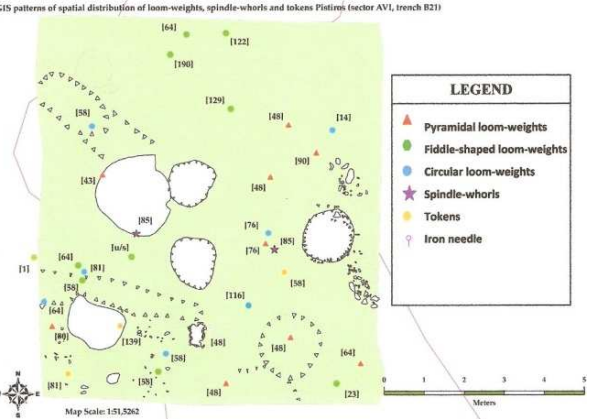

Map 1. GIS spatial distribution patterns of loom-weights, spindle-whorls and tokens at Pistiros (sector AVI, trench B21) (plan in Auto Cad prepared by $M$. Adams)

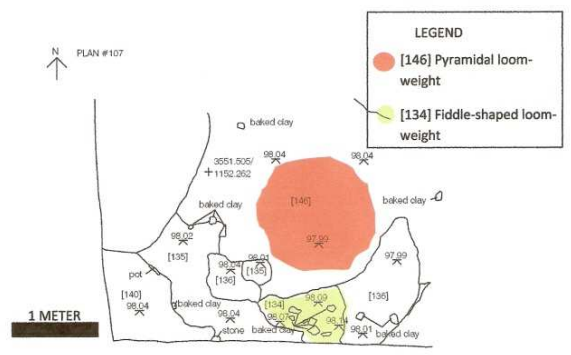

Map 2. GIS spatial distribution pattern of loom-weights in B21, within contexts [134] and [146] (plan in Auto Cad prepared by M. Adams)

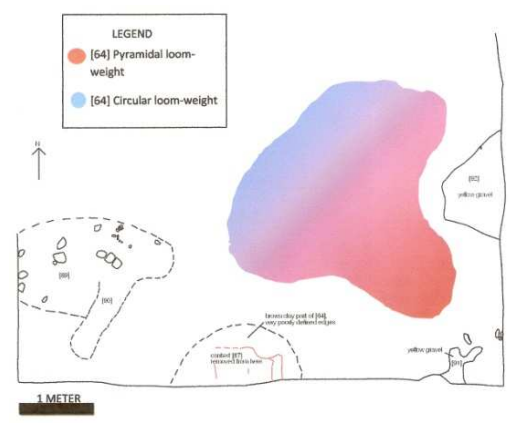

Map 3. GIS spatial distribution pattern of loom-weights in B21, within contexts [64] (plan in Auto Cad prepared by M. Adams)

Existence of various traces of past human activities within trench D19/24 suggests utilization of this area for domestic purposes. Presence of artefacts associated with textile production supports hypothesis about private character of space in square D19/24;Error! No se encuentra el origen de la referencia.. For other articles about analysis of spatial distribution patterns of archaeological artefacts in social context on Roman sites see papers of Eckardt and Allison ${ }^{1}$.

${ }^{1}$ Allison, 2006: 1-20; Eckeardt, 2005: 139-160;

\section{TOTAL NUMBER OF ARTEFACTS IN}

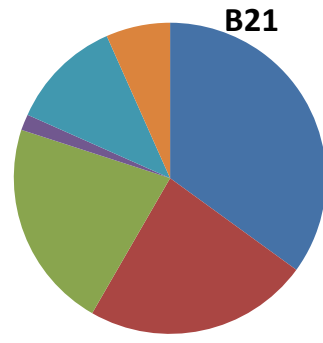

- PYRAMIDAL

LOOM-

WEIGHTS

FIDDLE-

SHAPED

LOOM-

WEIGHTS

Chart 1. Total amount of loom-weights (pyramidal, fiddle-shaped and circular), spindle-whorls and tokens within trench B21, sector AVI, at Pistiros

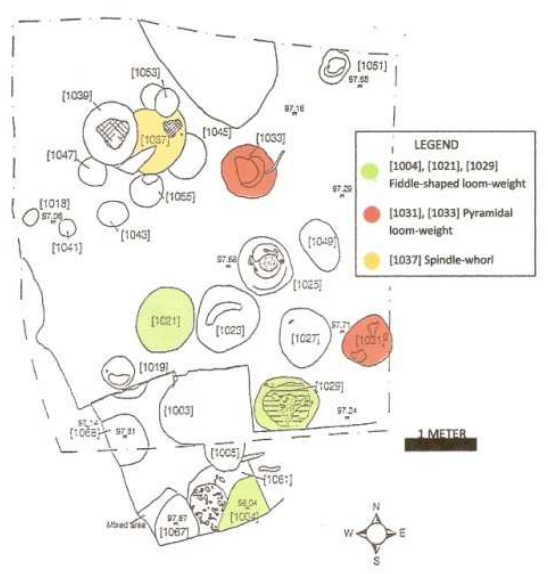

Map 4. GIS spatial distribution pattern of loom-weights in D19/24, within contexts [1004], [1021], [1029], [1031], [1033] and [1037] (plan after Archibald, 2007: Fig. 2, p. 100)

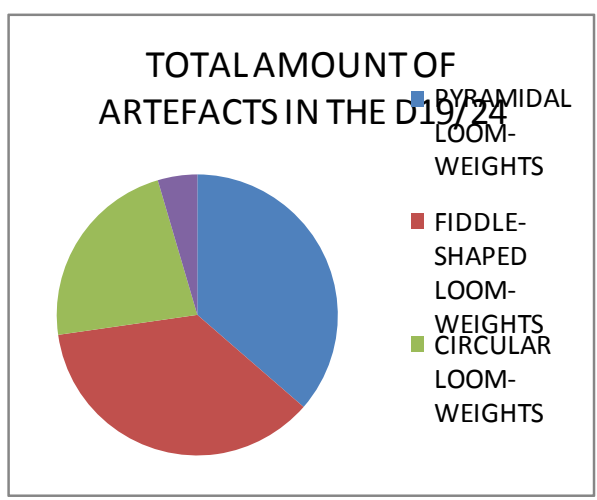

Chart 2. Total amount of loom-weights (pyramidal, fiddle-shaped and circular), spindle-whorls and tokens without available EDM coordinates within trench D14/19 and D24, sector AVI, at Pistiros.

5. Loom-weights and spindle-whorls in cultural, social and economic context 
Archaeological material associated with spinning and weaving from Pistiros can reveal interesting information about the mixed Thraco-Greek population, where people of different origins were able to exist together creating positive mutual relationships (BOUZEK, 1996: 118). Although a female presence in the emporion has left no clear traces in the form of names engraved on pottery sherds (DOMARADZKA, 1996: 89-96; DOMARADZKA, 2002: 209-228; DOMARADZKA, 2007: 221-235), artifacts associated with the textile industry, besides handmade pottery and domestic architecture, make an analysis of the female input in the population possible.

Spinning and weaving were considered to be female occupations in antiquity. Although neither loom-weights nor spindle-whorls attest such an assumption directly, such a view point is widely accepted on the basis of information from ancient literary sources (Xenophon in Economics or Homer in Iliad and Odyssey) and paintings on domestic vessels depicting women weaving (Fig. 7). Young girls were taught this craft at an early age (Xen., Oec. 7.5). They used such valuable skills to produce textiles as clothing or bedding for members of the household. Any remaining surpluses of garments or bed-cloth could be sold on the local market. Moreover, this important activity was performed by both free and slave women of different ages (Hom., Od. 7.103-6). Spinning and weaving were considered symbolic reflections of female virtues based for example on the image of Penelope in the Odyssey. Thus, they were occupations representing honest women from the aristocratic, noble family or rich female individual of high rank (BOUZEK, 1996: 117).

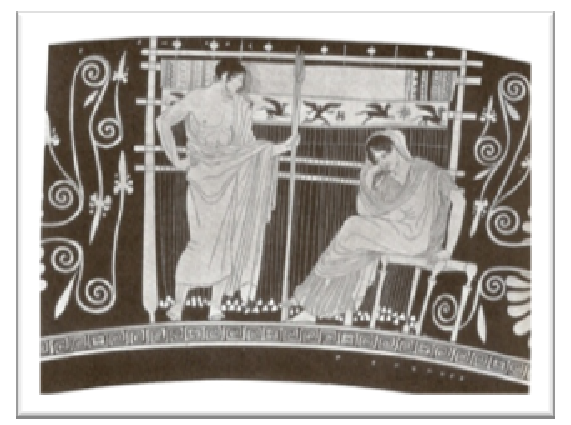

Figure 7. Painting on the Red-figured skyphos representing Penelope weaving (after Cabill, 2002: Fig. 37)

Vertical looms were the common type in the Mediterranean region. A web threads were weighted with ceramic loomweights. Once the weaving equipment was set up, it could not be moved to another place until the entire process was completed. As spinning and weaving were complex occupations requiring careful, patient and precise approach of well skilled individual, they were both time-consuming. Therefore, the choice of the place for the loom had to be carefully made to assure comfort for the weaver, as well as protection of the woven material against changing weather conditions (CAHILL, 2002: 170-171). Ancient writers gave us a glimpse into the selection of proper space for spinning and weaving within the house (Hom., Od. 1.361, 15.517, Hom., Il. 22.440).

Both the spindle and the loom were usually made of wood, therefore any remains have not survived to our times, as vulnerable to destruction processes as the textiles were. Therefore, this activity is archaeologically represented by ceramic spindle-whorls and loom-weights. The majority of loom-weights, spindle-whorls and tokens found in Pistiros were made of both coarse and fine red, grey or brown local clay of different tints, with visible white fine and coarse inclusions of quartz and mica in various quantities. Most of the objects were characterized by smoothly finished plain surface with drilled one or two holes. Some artefacts reveals traces of burning. They represent an interesting variation in shapes, sizes and weights. Different types and varieties of loom-weights can be related to existence of different kinds of loom or with the material produced such, as linen and cotton. The size and weight of loom-weights probably had a bigger impact on the choice of their use, for example lighter materials, such as linen required lighter weights, while thicker textiles, such as wool needed heavier weights, whereas the heaviest weights were probably applied to production of carpets (BOUZEK, 1996: 117-118).

The richest women possibly had their spindle-whorls and loomweight made by professional potters, while ordinary individuals probably made elements of their weaving equipment themselves at home. Spindle-whorls ground from sherds probably represent poorer groups within the female community in Pistiros, while the finest items might have belonged to women of a higher social status. Moreover, loom-weights were very personal objects because they were usually made and fired within domestic space and marked by finger prints or signet rings (Fig. 8), (Fig. 9). Such signet imprints on the loom-weigh indicated the noble position of woman from aristocratic social group as such ring was a symbol of dignity. The B and C types of loom-weights were shaped by female hands at home and marked by their producer and user by the fingertip imprints which were indeed a very personal signs. Moreover, type B could have been preferred by Thracian women, and a great accumulation of fiddle-shaped loom-weights may indicate considerable Thracian domination of females in the community of the emporion. It has been suggested that decorated whorls resembles Thracian cultic vessels, and therefore may have belonged rather to Thracian then Greek women from Pistiros. Furthermore, some loom weights, like B and C types were shaped hastily, with temper or careless approach, while other one carefully made with patience and precision, which can reflect, to some degree female character and personality (BOUZEK, 1996: 117-118; BOUZEK, 2002: 347-348; BOUZEK, 2007: 286; ONDREJOVA, 2007: 243-246).

But loom-weights, spindle-whorls and tokens could be used for other purposes than spinning and weaving as well. Utilization of objects with some visible irregular characteristics could be perceived from different perspectives. The high concentration of finds associated with weaving in the area of low altars escharai (B'2 and B22) suggests that they could act as offerings; loomweights of miniature proportions could rather have been used as toys as well; clay-objects similar to spindle whorls, but without central whole can be indentified as tokens used for games (BOUZEK, 1996: 117-118); some items could serve as a weight for fishnet; other might be worn as amulets (Fig. 10). 


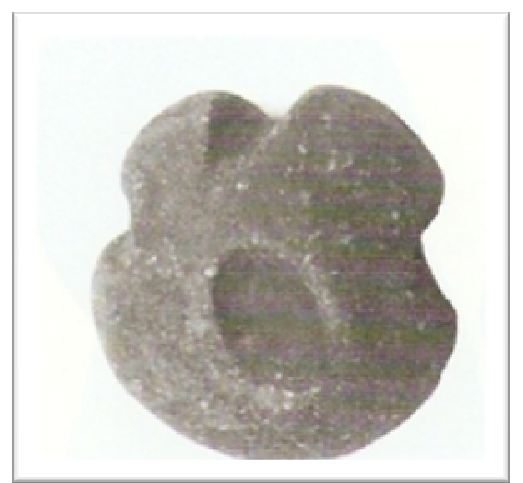

Figure 8. Fingertip imprint on a fiddle-shaped loom-weight (after Bouzek, 1996: Pl. XXXIX. 11.6:5)

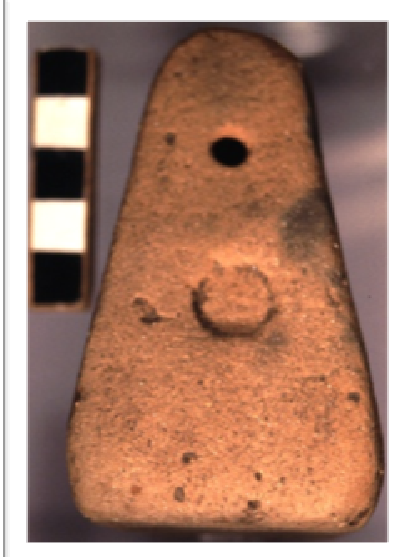

Figure 9. Signet imprint on the pyramidal loom-weight from trench B21 [80] (picture made by Z. H. Archibald);

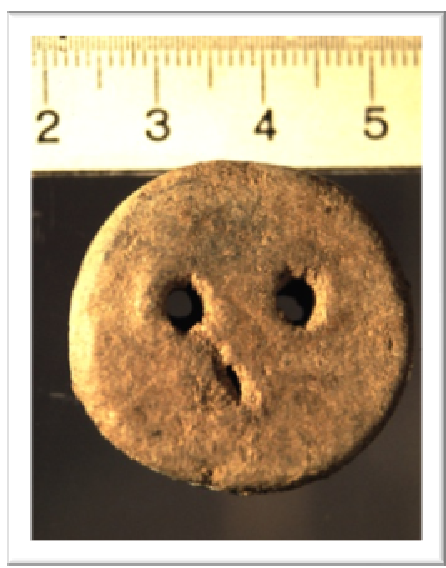

Figure 10. Backed-clay disk-amulet from B21 [81] (picture made by Z. H. Arcbibald)

\section{Conclusions}

The existence of spinning and weaving equipment within domestic space indicates the importance of textile production for household needs. The distribution of loom-weights, spindle-whorls and tokens marks specific areas destined for spinning and weaving within houses. This private space was used by female members of the family who produced different kinds of looms. Furthermore, archaeological evidence of spinning and weaving processes reveals information about cultural norms accepted and practiced by inhabitants of Greek emporion Pistiros in central Thrace in the classical period. Various characteristic features of loom-weights, spindle-whorls and tokens, as well as signs incised on those objects in the form of finger tip or signet imprints uncover some secrets of female's personality and social status. Moreover, a great accumulation of type B loom-weights which resemble Thracian cult vessels can be interpreted as an indication of the domination of women of Thracian origin within the society of Pistiros in the 5th and 4th/ 3rd centuries B.C. Finally, loom-weights, spindle-whorls and tokens could serve for other purposes than textile production such as religious offerings, cult amulets, gambling equipment, weights for fishnet or toys for children. Therefore, all necessary activities associated with the manufacture of materials can be perceived in social, cultural, economic context.

\section{Indication for further research}

The extensive and complex nature of archaeological material from the ancient emporion Pistiros suggests the possibility of applying numerous investigative approaches. Only broad and cooperative studies can provide us with as complete picture of past human activities on the site as possible. Preliminary research on artefacts associated with textile industry has already been conducted and published (BOUZEK, 1996: 117-166; BOUZEK, 2002: 347-348; BOUZEK, 2007: 286) but such wide archaeological evidence requires more precise and systematic analysis to be performed in the near future, including detailed investigation of variations in material, shape, size, weight and decoration of loom-weights, spindle-whorls and tokens in the cultural, social and economic context. Moreover, systematic spatial mapping procedures by utilization of GIS computer techniques and interpretation of spatial distribution patterns of finds in the comparative manner will enhance our understanding of human existence at this location. 


\section{Acknowledgements}

I would like to express my gratitude to my supervisors, Doctor Zofia Halina Archibald and Doctor Matthew Peter Fitzjohn of the University of Liverpool, who provided me with necessary supervision, help and advice at various important stages of the work. This article profited much from their professional academic experience, felicitous comments and valuable criticism.

\section{References}

\section{ANCIENT SOURCES}

HOMER, Iliad. Translated by E.V. Rieu (London 2003).

HOMER, Odyssey. Translated by R. A. Lattimore (London 2007).

XENOPHON, Economics. Translated by S. B. Pomeroy (Oxford 1994).

\section{MODERN LITERARTURE}

ALLISON, P. M. (2006): “Mapping for gender. Interpreting artefact distribution inside 1stand

2nd-century A.D. forts in Roman Germany", in Archaeological Dialogues, no 13/1, pp. 1-20.

BOUZEK, J. (1996): “Textile industry”, in Bouzek, J., Domaradzki, M., Archibald, Z. H. Pistiros I: excavations and studies. Prague. Charles University Press. pp. 117-166.

BOUZEK, J. (2002): “Addenda to Pistiros I. 1. The beginning of the emporion; 2. The routes; 3 . The fortifications and the city planning of Pistiros; 4. The textile industry", in Bouzek, J., Domaradzka, L., Archibald, Z. H. Pistiros II: excavations and studies. Charles University in Prague. The Karolinum Press. pp. 343-348.

BOUZEK, J. (2007): “Addenda II: Loom-weights, North Greek wares, Chemical analysis, City wall, Tombs, Coin hoard”, in Bouzek, J., Domaradzka, L., Archibald, Z. H. Pistiros III: excavations and studies. Charles University in Prague. Faculty of Philosophy. Prague. pp. 286.

CAHILL, N. (2002): “Household and City Organization at Olynthus”. Yale University Press. New Heaven and London.

DOMARADZKA, L. (1996): “Graffiti”, in Bouzek, J., Domaradzki, M., Archibald, Z. H. Pistiros I: excavations and studies. Prague. Charles University Press. pp. 89-94.

DOMARADZKA, L. (2002): “Catalogue of graffiti discovered during the excavations at Pistiros-Vetren1988-1998. Part one: graffiti on imported fine pottery", in Bouzek, J., Domaradzka, L., Archibald, Z. H. Pistiros II: excavations and studies. Charles University in Prague. The Karolinum Press. pp. 209-228.

DOMARADZKA, L. (2007): “Catalogue of graffiti discovered at Pistiros-Vetren (1988-2004), Part two: Graffiti on pottery, used in the household”, in Bouzek, J., Domaradzka, L., Archibald, Z. H. Pistiros III: excavations and studies. Charles University in Prague. Faculty of Philosophy. Prague. pp. 221-235.

ECKARDT, H. (2005): “The social distribution of Roman artefacts: the case of nail-cleaners and brooches in Britain”, JRA 18, pp 139160.

ONDREJOVA, I. (2007): “Gem imprints on loom-weights: the running dog”, in Bouzek, J., Domaradzka, L., Archibald, Z. H. Pistiros III: excavations and studies. Charles University in Prague. Faculty of Philosophy. Prague. pp. 243-246. 